\title{
Clinical outcomes of interactive, intensive and individual (3i) play therapy for children with ASD: a two-year follow-up study
}

\author{
Elodie Tilmont Pittala ${ }^{1}$, Yann Saint-Georges-Chaumet ${ }^{2}$, Claire Favrot ${ }^{3}$, Antoine Tanet ${ }^{4,5}$, David Cohen ${ }^{4,5}$ \\ and Catherine Saint-Georges ${ }^{4, *^{*}}$
}

\begin{abstract}
Background: The outcomes of psycho-educational interventions for Autism Spectrum Disorders (ASDs) comorbid with severe to moderate intellectual disability (ID) are insufficiently documented. In this prospective study, we examined a developmental individual, interactive and intensive approach, called the ' 3 i method', which is based on play therapy.

Methods: Twenty DSM-IV-TR ASD subjects (mean chronological age $63.8 \pm 37.8$ months; mean developmental age 19. $5 \pm 6.6$ months) were included and followed the $3 i$ method for 24 months. Developmental and behavioural skills were assessed at baseline and after 24 months using the VABS, PEP-R and Nadel Imitation scale. Autism severity was evaluated using the Child Autism Rating Scale (CARS) and the Autism Diagnostic Interview (ADI-R).

Results: After 2 years of the $3 i$ method, our 3 primary outcome variables significantly increased (VABS developmental age of socialization increased by $83 \%$, age of communication by $34 \%$, and Nadel Imitation score by 53\%). Almost all VABS and PEP-R domains significantly improved. Additionally, increases in the VABS socialization score were positively correlated with the total number of treatment hours and CARS score; all ADI-R areas significantly decreased; and diagnoses had changed in $47.5 \%$ of the subjects (37\% for PDD-NOS and even 10.5\% for ID without PDD).

Conclusion: Children who followed the $3 i$ method for 2 years had significantly improved behavioural and developmental skills and showed a clear decrease in autism severity. These results suggest that the $3 i$ method may be useful for autistic children by improving their daily interactions with their social environment.
\end{abstract}

Trial registration: was retrospectively registered on May 20th, 2014 by the French Agency for drug and health (ANSM) under number ID-RCB 2014-A00542-45, reference: B148558-31.

Keywords: Autism spectrum disorders, Developmental intervention, Play-therapy, 3i method

\section{Background}

Autism spectrum disorder (ASD) is a life-long neurodevelopmental disorder characterized by early impairments in socio-communicative skills that are associated with a set of restricted interests and/or repetitive stereotypical behaviour [1]. Recently, the fifth edition of the Diagnostic and Statistical Manual of Mental Disorders (DSM V) added sensory impairments to the diagnostic criteria of

\footnotetext{
* Correspondence: catherine.saintgeorges@gmail.com

${ }^{4}$ Department of Child and Adolescent Psychiatry, Hôpital de la

Pitie-Salpêtriere, University Pierre and Marie Curie, 75013 Paris, France

${ }^{5}$ Institut des Systèmes Intelligents et de Robotiques, CNRS UMR 7222,

Université Pierre et Marie Curie, Paris, France

Full list of author information is available at the end of the article
}

the behavioural manifestations of ASD [2-4]. Many research efforts have been made to identify precursors of ASD, leading to a significant decrease in the age of diagnosis [5], which enables earlier treatment. The existing treatments are mainly symptomatic.

Behavioural methods, which aim to develop certain expected behaviours through child reinforcement, have been proposed to treat ASD with significant scientific support [6, 7]. Applied Behaviour Analysis (ABA) is a one-toone intensive approach based on behavioural strategies and targets specific symptoms using reinforcement of adaptive, expected skills $[8,9]$. After criticisms regarding the lack of spontaneity in this early approach, Pivotal Response Training was subsequently developed and uses

(c) The Author(s). 2018 Open Access This article is distributed under the terms of the Creative Commons Attribution 4.0 International License (http://creativecommons.org/licenses/by/4.0/), which permits unrestricted use, distribution, and 
children's own choice of games and activities to reinforce the correct answers expected by the professional; this type of training also favours providing complete or incomplete forms of attempts to respond, alternating between acquisition and maintenance, and using intrinsic reinforcers [10]. Additionally, the Treatment and Education of Autistic and related Communication handicapped CHildren (TEACCH) program emphasizes a close working relationship between parents and practitioners, adapts the intervention to the characteristics of the child and uses structured teaching educational techniques [11].

Alternatively, developmental approaches start from the specific interests and resources of the child and aim to restore the global developmental process to increase communication skills and learning ability. One example is the Son-Rise Program ${ }^{\circ}$, developed in the early eighties, which was essentially based on "joining" the child, playing with him and following his cues. This program has been followed by tens of thousands of families in the U. S.A., and a recent study based on 5 days of intensive treatment of 6 children showed encouraging results [12]. Other developmental interventions based on play therapy have conceptualized the relationship between playing and child development, such as Floor Time [13, 14] or in France, "Exchange and Development Therapy" (EDT), which was developed in the 1990s by Lelord [15]. Floor Time consists of sequences of guided play (15$20 \mathrm{~min}$ ) that are repeated several times by parents throughout the day and are supervised by an expert. Floor Time is the core of the Developmental, Individual Differences, and Relationship-based (DIR) method. DIR focuses on individual developmental differences in a child's emotional functioning, information processing, motor planning and types of interactions. The DIR method recommends following the child's lead and supporting his/her initiative; focusing on joint attention; closing circles of communication; creating semistructured problem solving approaches; contrasting repetitiveness with playful obstruction; supporting visual attention; and working on imitation [16, 17].

Some methods mix elements of developmental play therapy with a structured and behavioural teaching approach. The Braintraining method [18] associates guided play time with teaching material depending on the specific developmental stage of the child's playing ability. Multisensory activities help increase the child's level of multimodal integration, overcoming difficulties that would restrict the development of more sophisticated cognitive skills such as symbolic play, language and social understanding. The Early Start Denver Model (ESDM) is an early and intensive intervention approach for young children that combines developmental and behavioural approaches. This method was evaluated in a randomized control trial with 48 toddlers [19], and the study showed that ESDM effectively improved cognitive and adaptive behaviour and reduced the severity of ASD diagnoses. A complementary electro-physiologic study suggested that a certain normalization of brain function was associated with clinical improvement [20]. In recent years, the ESDM has aroused great interest; for example, a study on at-risk infants suggested increased developmental abilities and a decrease in autism severity after 3 years of ESDM treatment [21]. Some behavioural therapists have also tried stimulation with small children using their favourite games and activities and showed a sustained improvement in social interactions [22]. Thus, the concept of triggering developmental processes in children with ASD has advanced in the scientific community.

In France, health facilities often provide institutional approaches to develop relational skills through various activities and therapeutic mediations, in groups or individually [23]. These approaches have increasingly been associated with structured tools from an integration perspective; for example, the ESDM has recently been integrated into the French health care service [24]. A previous review highlighted the diversity of practices in France but also the lack of published data on the effectiveness of these institutional strategies [25]. A French multicenter study is currently underway to evaluate the effectiveness of an integrated, individual, intensive structured teaching program provided to children with ASD and moderate intellectual disability (ID) in institutional care [26].

Beyond the diversity of individual approaches, an analysis of the literature has provided some important guidelines for improving the treatment of ASD children [27], including the following: i) Diagnose and start interventions early; ii) provide at least three or 4 hours of treatment each day; iii) center interventions on family involvement, placing parents in a position that allows them to actively participate in the education of their child; iv) provide regular updates on progress and subsequent goals; v) choose between behavioural or developmental treatment depending on the child's response; vi) encourage spontaneous communication; vii) include interactions with peers as soon as possible; viii) help extend the acquired skills to various environments and natural contexts; and ix) support positive behaviours rather than tackling challenging behaviours [25, 27]. Notably, previous studies suggested that involving the family in the treatment of the child promoted the therapeutic effect. For example, in a French study on a 20-month home-intensive method involving the family, 25 children progressed from 6 to 25 points in their developmental quotient [28]. In addition, a randomized controlled Australian study showed that parental involvement through home-specific work promoted the efficiency of treatment $[29,30]$. Similar results, showing beneficial effects of parental contribution in early intervention, have been 
published and highlight the importance of parental involvement in treating ASD [30-32], even for long-term outcomes [33].

In this study, we examined a developmental, Individual, Interactive and Intensive approach to treat ASD comorbid with ID called the '3i method', which was based on the playing ability of the child and included the family. As this play therapy was meant to stimulate developmental processes, the child's progress was analysed by a psychologist through regular team meetings, considering the normal developmental pattern of a child of his/her developmental age. Here, we present a prospective exploratory study that aims to assess the outcome of 20 ASD subjects who followed the $3 \mathrm{i}$ method for 24 months. Using appropriate scales, we estimated the course of developmental and behavioural skills and autism severity after 2 years.

\section{Methods}

\section{Participants - ethics}

This study's protocol was approved by the institutional ethical committee and was retrospectively registered on May 20th, 2014 by the French Agency for drug and health (ANSM) under number ID-RCB 2014-A0054245, refence: B148558-31 (Additional file 1: Protocol). All parents of the subjects spontaneously contacted the Association Autisme Espoir vers l'Ecole (AEVE) to help them provide $3 \mathrm{i}$ treatment for their children. In total, $37 \%$ of the parents discovered AEVE through its website, $38 \%$ through relatives, $16 \%$ through meetings or other media and $9 \%$ through health caregivers. The parents voluntarily provided informed consent to include their child in the study after being informed of the study design and goals.

The inclusion criteria were as follows: being diagnosed with ASD based on the Autism Diagnostic Interview, Revised (ADI-R) and the Childhood Autism Rating Scale (CARS); initiating the $3 \mathrm{i}$ method at some point between January 2013 and December 2013; residing in an environment that allowed for the correct application of the $3 \mathrm{i}$ method (possibility of a dedicated room, ability to recruit and keep volunteers, as determined by the AEVE's headmaster); not receiving any other ASD intervention treatment method (e.g., ABA or TEACCH); and having French as their maternal language. The exclusion criteria were as follows: the presence of associated diseases such as epilepsy or Rett syndrome; Asperger's syndrome; and the inability to ensure $3 \mathrm{i}$ treatment for the entire duration of the study. Patients aged $>15$ years old at the beginning of the study were not included. Asperger patients, with their outstanding intellectual abilities, were not considered for this study as a standard 3i program would need to be customised to their abilities, and the volunteers would need a special training.
During the one-year selection period (January to December 2013), 31 children began the 3i program, but only 20 were included in this study. Four of the eleven remaining children were outside the age range (too old), three presented Asperger's syndrome, two suffered from epilepsy, and two could not receive intensive $3 \mathrm{i}$ treatment. All the included subjects were not attending school and followed the $3 \mathrm{i}$ method between 30 and $35 \mathrm{~h}$ per week. Specifically, 17 children followed the $3 \mathrm{i}$ method at home and 3 at the AEVE Courbevoie day centre. The patients' age at the beginning of the study ranged between 2.8 and 14.5 years.

\section{3i method}

The 3i method is promoted by AEVE, a non-profit association founded in 2006. The 3i method is derived from the SonRise ${ }^{\bullet}$ Program but has important differences. Similar to SonRise ${ }^{\circ}$, the intervention occurs in a specific room devised for one-on-one interaction and designed to reduce unwanted sensorial stimuli. The basic intervention principles are also the same and are directed towards "joining" the child's world without any expectations through playful reactions to the child's cues [34]. However, the $3 i$ method also i) focuses on the sensory specificities of the child, ii) provides participants with a developmental roadmap that improves understanding of the present abilities and difficulties on their developmental path, and iii) distinguishes three developmental age stages in their corresponding agenda ( 0 to 18 months, 18 to 36 months and older than 36 months [35]).

The 3i method presents important similarities with Exchange and Development Therapy (EDT), which is practised in France and is based on approximately two 45min sessions each week [15]. The key aspects of this therapy are as follows: i) a quiet environment to limit excessive neural reactivity in the child to sensorial stimuli; ii) openness of the therapist, lack of expectations, and careful observation; and iii) facilitation of reciprocity by, for example, free imitation [36].

However, the $3 \mathrm{i}$ method is recommended to be intensive: a minimum of $30 \mathrm{~h}$ of play sessions per week in a specific playroom are proposed. Each game session lasts 1 and onehalf hours. The recommended size of the playroom is approximately 10 sq.m., which offers a space with boundaries visible by the child. The lighting must be subdued, and the sounds should be muffled with appropriate ground lining. The standard equipment in the room includes shelves out of the child's reach where objects will be visibly stored, a mirror, a swing and a few other items used to gain a physical perception of oneself; these items can be visual such as clay, tactile such as colour cubes, and auditory such as a triangle or xylophone, in addition to picture books, puppets, etc. The sessions are conducted by volunteers. These participants are mostly non-professionals in the field of ASD. Volunteers are first screened by the parents and then 
participate in a meeting with the head of AEVE, who provides them with information regarding autism and the $3 \mathrm{i}$ method. They are screened based on their ability to ensure good care for children before beginning to interact with the child in the playroom. They subsequently participate each month in a group session with the other participants, together with the parents, under the supervision of a 3itrained psychologist (who is paid by the parents). For each child, this 3i-trained psychologist manages the team of volunteers and ensures the consistency of their actions and their compliance with the $3 \mathrm{i}$ method. The child's progress is recorded and analysed by the psychologist, who provides some advice according to the participants' questions and the child's evolution.

The $3 \mathrm{i}$ intervention is organized into three phases that correspond to the developmental age brackets of 0 to 18 months (Phase 1), 18 to 36 months (Phase 2), and over 36 months (phase 3). During phase 1, the intervention is centred on simple sensorial games and exchanges, without recourse to many objects. The aim is to help children discover themselves, their body and the distinct existence of another person. During phase 2, the child's attention is brought to the external world outside the playroom, a meaningful language emerges, and the child gains access to symbolic play. The child's desire for actual conscious learning appears in phase 3 and leads to progressive integration into a classroom as a classmate, without being seen as a handicapped child. The $3 \mathrm{i}$ method has been used in different countries, particularly in Poland, where the $3 \mathrm{i}$ method has been extensively described [35, 37]. The method was also carefully described in a recent retrospective study investigating the effect of 2 years of the $3 \mathrm{i}$ approach on the socio-communicative skills of 120 ASD children (Favrot C, Saint-Georges-Chaumet Y, SaintGeorges C: Evaluation of the efficiency of the 3i method from a retrospective archive study on 120 children diagnosed with Autism Spectrum Disorders, submitted). In addition, a retrospective single case study with 10 years of follow-up shows the long-term positive effects of the method (Astrup O: An individual study of an autistic child over a nine years period using the $3 \mathrm{i}$ method, in preparation). Despite these different sources of information, the method has not yet been manualized.

\section{Clinical variables}

Three variables were chosen as the primary measures: developmental age in the Vineland Adaptive Behaviour Scale (VABS), communication and socialization scores and the Nadel imitation scale (NIS) score [38]. The secondary outcomes were the developmental ages of imitation and verbal communication according to the Psycho-Educational Profile - Revised (PEP-R) scale and the severity of autism according to the CARS. The ADI-R was also used to assess diagnosis status and eventual changes.
The VABS is a measure of adaptive behaviour [39] that was designed to assess handicapped and non-handicapped persons (birth to 18 years and low functioning adults) in their personal and social functioning. Split-half and testretest reliability coefficients for the composite scores are good, ranging from median values of 0.83 for the motor skills domain to 0.94 for the composite score. Interrater coefficients are lower for the same measures: 0.62 to 0.78 [40]. For validity, correlations with concurrent measures (the original Vineland, the $\mathrm{ABIC}$, the $\mathrm{K}-\mathrm{ABC}$, and the PPVT-R) were shown to be low to moderate, with generally higher coefficients obtained when the comparisons were made on subjects with handicapping conditions. We used it here to assess the impact of the $3 \mathrm{i}$ method on the development of socialization, communication, and autonomy in everyday life. Since we do not have tables for converting raw scores into standard scores from sampling in the French population, the results of the evaluations are expressed in months of developmental age. The NIS [38] was added as a primary variable because we aimed to include children with severe intellectual disability as well (developmental age $<18$ months), for whom the NIS is better suited, because imitation is a very early skill in development. The NIS provides preverbal communication scores, with a focus on imitation. It contains three items: spontaneous imitation, recognition of emulation and imitation on request. An analysis of the scores obtained in the three evaluation times (T0, T1, and T2) offers finer monitoring of the impact of the $3 \mathrm{i}$ method on the development of non-verbal communication, particularly in very young or nonverbal subjects.

The PEP-R test is used to calculate the patient's developmental age at different evaluation times in the following developmental areas: imitation, perception, fine motor skills, global motor skills, oculo-manual coordination, cognitive performance, and verbal cognition according to behavioural observations [41]. A developmental age can be calculated for each of these areas. PEP-R psychometrics were studied in a sample of 116 children with the dual disability of an intellectual disorder and autism. PEP-R demonstrated a good internal consistency (Cronbach's $\alpha$ ranging from 0.91 to 0 . 93) and domain total correlation (ranging from 0.75 to 0. 90). The interrater reliability (intraclass correlation coefficient, ICC $=0.96)$ and test-retest reliability $(\mathrm{ICC}=0.87)$ were good, and there was moderate-to-high concurrent validity with Gesell's Developmental Schedule (r ranging from 0.61 to 0.82 ; all $P=0.001$ ) [42]. In this study, we specifically focused on the imitation and verbal cognition developmental ages because they were deemed more significant prerequisites of successful school (re)entry.

The ADI-R is a diagnostic assessment tool based on the description and history of the patient that analyses his/her development in three areas: quality of social interactions, communication and language, and restricted interests and 
stereotyped behaviours [43]. The ADI-R has good reliability and validity and is currently considered the gold standard for diagnosing children with autism for research purposes. We chose to use the ADI-R rather than the ADOS 2 because it allows a more global evaluation of children's abilities in various ecological contexts and not only in the context of a formal evaluation with an unknown observer. Parents are often very informative because they are close observers of their child's behaviours. Although parental reporting could lack objectivity, other tools such as the CARS and PEP-R were scored through an external observation; thus, ADI-R appeared complementary to these spot observations. The ADI-R was used 3 times during this study as a secondary criterion to assess the efficacy of the method.

The CARS was developed to identify and classify children with autism and to determine symptom severity through quantifiable ratings based on direct observation. CARS interrater reliability is good from 0.55 to 0.93 , and for validity, the CARS yielded results consistent with the judgements of clinical experts [44]. The following 15 items assessed are those typically disrupted in autism: social interaction, imitation, emotional response, body use, use of objects, adaptation to change, visual responses, auditory responses, tastesmell-touch (and answer mode exploration), fear and anxiety, verbal communication, nonverbal communication, activity level, intellectual level and homogeneity of intellectual functioning; finally, a global perception of the subject is generated. CARS was used in this study to characterize the intensity of autistic disorder and its evolution during treatment.

\section{Study design}

Evaluations were conducted at the usual treatment location. Developmental and behavioural skills assessments with the PEP-R, VABS and NIS were performed by the first author and another psychologist through an observational session and a parental interview within a month after the first day of treatment (T0), 1 year after beginning the treatment (T1) and finally 2 years after beginning the treatment (T2). In addition, the severity of the autistic syndrome was evaluated through the ADI-R (parental interview administered by 3 external psychologists not working with the child) and CARS (some by external psychologists, others by the

Table 1 Calendar of outcome assessments

\begin{tabular}{llll}
\hline & T0 & T1 & T2 \\
& $(+1$ month $)$ & $(+12$ months $)$ & $(+24$ months $)$ \\
\hline ADI-R & $x$ & $x$ & $x$ \\
CARS & $x$ & $x$ & $x$ \\
VABS & $x$ & $x$ & $x$ \\
PEP-R & $x$ & $x$ & $x$ \\
IMITATION (Nadel) & $x$ & $x$ & $x$ \\
\hline
\end{tabular}

psychologist who supervised the method) at the beginning (T0) and end of the study (T2) (Table 1).

During the 2-year follow-up, the total duration of participation (patient and parent) in the specific assessments was approximately $22 \mathrm{~h}$. The evaluations occurred in the child's usual playroom and in a place suitable for parental interviews. To optimize the evaluation sessions, the playroom was designed to exclude anything that could distract the patient during the assessment (slide, swing, mirror, etc.). The playroom was equipped with only two chairs and a table, two cameras on tripods and the evaluation materials.

\section{Statistics}

Three subjects left the study before undergoing the T2 tests for the VABS, PEP-R, NIS, CARS and ADI-R. The $\mathrm{T} 2$ missing values were inferred by replacing their T2 with $\mathrm{T} 1$ values in accordance with the "Last Observation Carried Forward" method [45]. The low data homogeneity and small number of subjects implied the use of non-parametric tests to assess differences between the three evaluation times. A multiple comparison of paired measures was performed with Friedman's test. A post hoc analysis (to determine which group of measures differed from the others) was performed if the Friedman test was positive with the Bonferroni correction. $P$-values were considered significant at $p<0.05$. Statistical analyses were performed using $\mathrm{R}$ software version 3.2.1.

\section{Results}

\section{Subjects}

Twenty subjects were enrolled in the present study between January 2013 and March 2014. All participants were diagnosed with ASD according to the DSM-IV-TR criteria [46]. More specifically, according to the ADI-R scores, all subjects met the criteria for autistic disorder [43]. Boys represented $90 \%$ (18 out of 20 ) of the study sample (Table 2).

Table 2 Sample description at baseline

\begin{tabular}{ll}
\hline Characteristics of subjects at inclusion & \\
\hline Number & 20 \\
Sex & Boys: 18; Girls: 2 \\
Chronologic age (months \pm SD) & $63.8 \pm 37.8$ \\
$\begin{array}{l}\text { Developmental age (month } \pm \text { SD, from } \\
\text { global PEP-R score) }\end{array}$ & $19.5 \pm 6.6$ \\
$\begin{array}{l}\text { Developmental quotient (mean } \pm \text { SD from } \\
\text { global PEP-R developmental age) }\end{array}$ & $35.3 \pm 13.1$ \\
Type of communication (\%) & Nonverbal: $13(65 \%)$ \\
& Gestures: 1 (5\%) \\
& Babbling: 2 (10\%) \\
Total duration of treatment (hours \pm SD) & Verbal: 4 (20\%) \\
\hline
\end{tabular}


The chronological age at the starting point varied between 33 and 173 months. However, the developmental ages calculated with the PEP-R test were more homogeneous, with a median developmental age of $19.5 \pm 6.6$ months (minimum 13, maximum 38). Additionally, 65\% (13 out of 20) of the subjects were initially categorized as nonverbal with regard to their mode of communication. Overall, the subjects spent $2832 \pm 550 \mathrm{~h}$ following the $3 \mathrm{i}$ method during the 2 years of their study period. This means that every patient had an average of $4 \mathrm{~h}$ of $3 \mathrm{i}$ sessions per day. All twenty subjects completed the baseline and first year's evaluations (T0 and T1). Three subjects dropped out after 1 year. One subject was placed by his parents into a medico-educative institution due to substantial progression. One patient dropped out because the parents rejected pursuit of the $3 \mathrm{i}$ method at home. The last patient was lost to follow-up. The results of developmental and behavioural skills and ASD severity are summarized in Tables 3 and 4, respectively. Individual results with the chronological age of the patients are presented in Additional file 2: Table S1.

\section{Developmental and behavioural skills}

All 3 principal outcomes increased significantly during the 2 years of the 3i method (Table 3, Fig. 1). The developmental age of communication according to the VABS increased significantly from $15.8 \pm 9.0$ to $21.7 \pm 11.2$ months, representing a $34 \%$ increase. Additionally, the developmental age of socialization according to the VABS increased significantly from $12.8 \pm 6.5$ to $24.3 \pm 13.4$ months, representing an $83 \%$ increase after 2 years of the 3i method. The NIS score increased significantly by $53 \%$, which is consistent with the $67 \%$ increase after 2 years of the $3 \mathrm{i}$ method in the PEP-R imitation developmental age (6.8 months). The PEP-
$\mathrm{R}$ verbal cognition score increased by only $23 \%$ after 24 months, which was not significant.

Additionally, of the 8 other items covered by the VABS and PEP-R evaluations, all increased significantly during the 24 months of the study, except for PEP-R global motor skills (Table 3 ). The overall results suggest that 24 months of the $3 \mathrm{i}$ method was associated with a global increase in developmental and behavioural skills among our 20 subjects.

\section{ASD severity}

In addition to developmental and behavioural skills, we assessed variation in ASD severity using the CARS and ADI-R with 19 patients (unfortunately CARS and ADI-R data at $\mathrm{T} 1$ and $\mathrm{T} 2$ are absent for one patient) (Table 4, Fig. 1 and Additional file 2: Table S1). Based on these results, the mean CARS score dropped significantly from $44.4 \pm 5$ to $33.7 \pm 5.1$ at the end of the 2 years. A CARS score $>37$ indicates severe autistic disorder; a score between 30 and 37 indicates slight to moderate autistic disorder; and scores under 30 indicate patients who are outside the ASD range. Based on this scale, $94 \%$ of our patients were considered severely autistic at the beginning of the study and $6 \%$ were considered moderately autistic. At the end of the 2 years, only $21 \%(4 / 19)$ remained severely autistic, 53\% (10/19) had progressed to a moderate autistic score, and 26\% (5/19) could be considered to no longer have autism (Fig. 1). In addition, all ADI-R areas (interaction, communication, and stereotypy) significantly decreased during the 24 months of treatment (Table 4 and Figure 1). According to the ADI-R, 9/19 (47.3\%) subjects had an improved DSM-IV diagnosis. Seven subjects' diagnoses changed from autistic disorder (AD) to Pervasive Developmental Disorder-Not Otherwise Specified (PDD-

Table 3 Variation in developmental and behavioral skills throughout the study

\begin{tabular}{lllll}
\hline Evaluation & T0 & T1 & T2 & P-value Friedman \\
\hline VABS Communication (mean \pm SD) & $15.8 \pm 9.0$ & $19.9 \pm 10.0^{* * *}$ & $21.7 \pm 11.2^{* * *}$ & $1.210^{-6}$ \\
VABS Socialization (mean \pm SD) & $12.8 \pm 6.5$ & $19.2 \pm 7.6^{* * *}$ & $24.3 \pm 13.4^{* * *}$ & $2.710^{-6}$ \\
Imitation Score Nadel (mean \pm SD) & $9.6 \pm 5.7$ & $13.4 \pm 7.1^{* *}$ & $14.3 \pm 6.3^{* *}$ & $6.510^{-5}$ \\
PEP-R Imitation (mean \pm SD) & $11.2 \pm 8.1$ & $16.0 \pm 11.8^{*}$ & $18 \pm 15.0^{* *}$ & $4.510^{-5}$ \\
PEP-R Verbal cognition (mean \pm SD) & $17.6 \pm 9.4$ & $22 \pm 13.0$ & $20.9 \pm 16.0$ & 0,207 \\
Global PEP-R (mean \pm SD) & $25.7 \pm 10.5$ & $30.9 \pm 13.5^{* *}$ & $33.5 \pm 17.0^{* * *}$ & $5.8310^{-6}$ \\
PEP-R Perception (mean \pm SD) & $28.5 \pm 12.6$ & $38 \pm 17.7^{* *}$ & $40.5 \pm 17.1^{* *}$ & $4.4810^{-4}$ \\
PEP-R Fine motor skills (mean \pm SD) & $30.6 \pm 14.7$ & $35.2 \pm 15.0^{*}$ & $39.7 \pm 17.2^{*}$ & 0.0147 \\
PEP-R Global motor skills (mean \pm SD) & $32.3 \pm 12.9$ & $41.0 \pm 14.4^{* *}$ & $34.0 \pm 20.3$ & $8.5910^{-3}$ \\
PEP-R Oculo-manual development (mean \pm SD) & $28.8 \pm 14.5$ & $35.5 \pm 16.5^{*}$ & $38.8 \pm 18.2^{* *}$ & $1.1210^{-3}$ \\
PEP-R Cognitive performance (mean \pm SD) & $21.9 \pm 14.8$ & $25.5 \pm 15.2$ & $26.9 \pm 19.0$ & 0.0293 \\
VABS Autonomy (mean \pm SD) & $23.1 \pm 9.7$ & $27.2 \pm 10.3^{* * *}$ & $32.1 \pm 12.4^{* * *}$ & $9.8710^{-7}$ \\
VABS Motricity (mean $\pm S D$ ) & $31.6 \pm 11.5$ & $37.5 \pm 12.4^{* *}$ & $38.5 \pm 14.1^{* *}$ & $2.3110^{-4}$ \\
\hline All scors are devel &
\end{tabular}

All scores are developmental age in months except for the imitation score based on the Nadel scale. The * indicates the level of the $p$-values of the post hoc tests between T0 and T1 and T0 and T2 after the Friedman test. Bonferroni adjustments were made due to the multiple analyses ${ }^{* * *} p<0.001 ;{ }^{* *} p<0.01 ;{ }^{*} p<0.05$ 
Table 4 Assessment of autism severity during the study

\begin{tabular}{lllll}
\hline Evaluation & T0 & T1 & T2 & $P$-value \\
\hline CARS & $44.5 \pm 5.0$ & $37.1 \pm 5.6^{* *}$ & $33.7 \pm 5.1^{* * *}$ & $1.7610^{-7}$ \\
ADI-R Interaction & $23.1 \pm 3.2$ & $14.6 \pm 3.8^{* * *}$ & $12.7 \pm 5.0^{* * *}$ & $1.2110^{-7}$ \\
ADI-R & $13.0 \pm 3.7$ & $10.6 \pm 3.1^{*}$ & $8.3 \pm 2.8^{* *}$ & $4.7710^{-5}$ \\
Communication & & & & \\
ADI-R Stereotypy & $6.4 \pm 2.6$ & $5.1 \pm 2.5$ & $4.0 \pm 2.1^{*}$ & 0.00235
\end{tabular}

The * indicates the level of the p-values of the post hoc tests between T0 and $\mathrm{T} 1$ and T0 and T2 after the Friedman test. Bonferroni adjustments were made due to the multiple analyses ${ }^{* * *} p<0.001 ;{ }^{* *} p<0.01 ;{ }^{*} p<0.05$

NOS), and 2 subjects were no longer categorized as having PDD. All individuals still had moderate to severe intellectual disability at the end of the study.

\section{Prediction of outcomes}

To test whether any baseline variables were correlated with the developmental and behavioural skills' evolution and the decrease in ASD severity observed, the correlations between each of the 3 principal outcome variables were tested with the following: the patient's chronological age at the beginning of the study, the developmental age (based on the PEP-R) at the beginning of the study, the developmental ratio (developmental age/chronological age) at the beginning of the study, the total duration of treatment and the CARS and ADI-R scores at the beginning of the study. Only the total duration of the treatment was positively correlated with the VABS socialization score (Fig. 2). This latter result suggests that a greater number of hours of treatment predicted better improvement in the VABS socialization score.

No noticeable difference could be observed between the three patients treated with the $3 \mathrm{i}$ method in a centre compared to those treated at home (Additional file 2: Tables S1 and S2). In addition, the progress of younger patients (beginning the $3 \mathrm{i}$ method before 5 years of age) was not significantly different from that of older patients, except for the imitation score of Nadel (Additional file 2: Tables S1 and 3). However, because of the low number of patients, these results must be interpreted with caution. Indeed, the increases in VABS scores were higher for younger patients, particularly for the socialization VABS score, which displayed a significant differential progression.

\section{Discussion}

Our sample consisted of a population of children who are rarely studied because they presented with severe ASD (mean CARS $=44.5$, Table 1 ) with moderate to severe intellectual disability (mean developmental quotient based on PEP- $R=35.3+/-13.1$ ) at the start of the study. In fact, numerous studies choose to exclude children with a developmental quotient (DQ) below 35 [19]. Our results showed that after 24 months of the 3 i method, our sample of 20 patients globally progressed in different skills including socialization, communication, perception and imitation. In line with these developmental changes, the severity of ASD significantly decreased: after 2 years of treatment, $26 \%$ of the subjects moved below the CARS threshold proposed for ASD (Table 4). Accordingly, several ADI-R diagnoses changed: although all patients were initially diagnosed with autistic disorder (AD), after 2 years of the 3i method, 9 out of 19 (47\%) had an improved diagnosis. These results appear to be encouraging, in particular because of the relatively old age of the subjects and the lower cognitive profile (mean $\mathrm{DQ}=35$ ) compared to well-designed randomized trials previously published [19].

Interestingly, the VABS socialization change ratio was positively correlated with the total duration of receiving the $3 \mathrm{i}$ method. This correlation may indicate one major effect of the $3 \mathrm{i}$ method. This variable was the only principal outcome that continued to significantly increase in $\mathrm{T} 2$ compared to $\mathrm{T} 1$. Indeed, the $3 \mathrm{i}$ method involves the

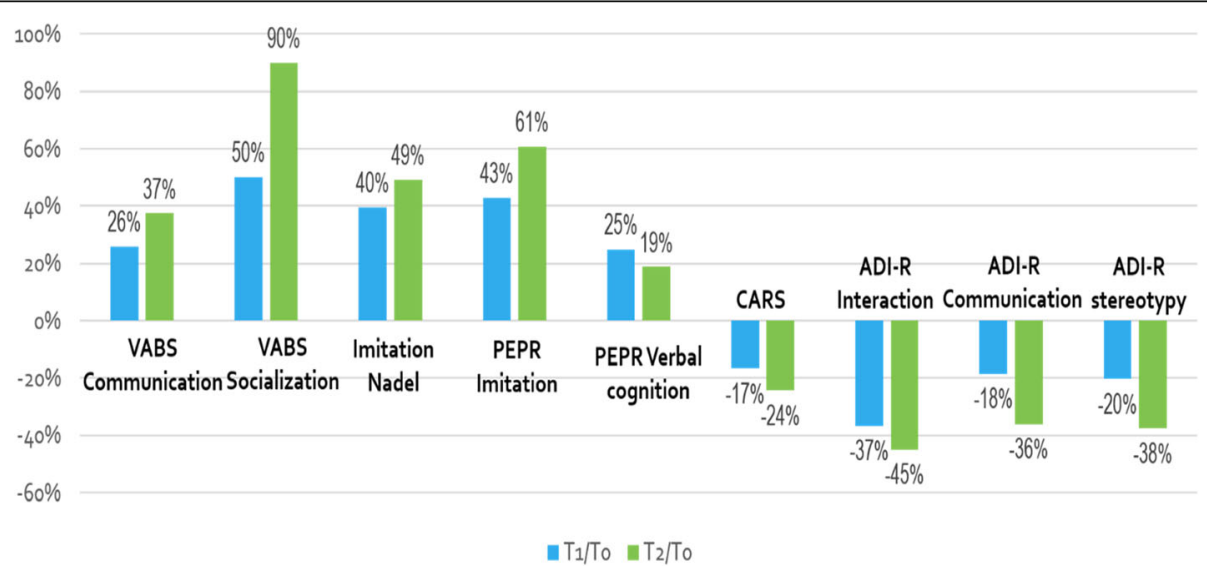

Fig. 1 Graph of the progression in behavioral and developmental skills and autism severity among subjects. The changes in median scores of the VABS developmental age. PEP-R developmental age. Nadel imitation scale and the CARS and ADI-R evaluations are reported according to the T0 values and expressed as a percentage 


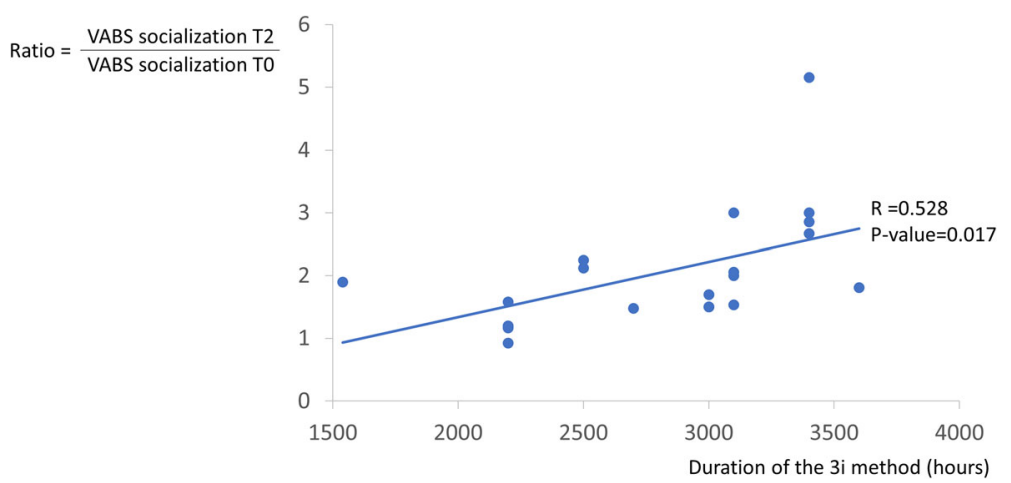

Fig. 2 Plot of the duration of the 31 method (in hours) and the ratio of the VABS socialization score at T2 to the VABS socialization score at T0 (baseline). A positive significant positive correlation was found ( $P$-value $=0.017$ ) between these two variables

use of multiple volunteers interacting several hours a day with the child. This intensive relationship may increase the socialization of the subjects in proportion to the hours spent in the playroom. This result may highlight one of the major interests of the $3 \mathrm{i}$ method for treating ASD children.

By contrast, no correlation between the subjects' age and the overall decrease in ASD severity/diagnosis or their progress in developmental skills was found. We also compared the progress of children aged $<6$ years $(N=$ $16)$ with those of children aged $>7$ years $(N=4)$. In accordance with the correlation test results, no statistically significant differences were observed between these two groups except for the imitation scale results (Additional file 2: Tables S1 and S3). This last result suggests that younger 3i patients may present a better improvement of imitation skills compared to older patients. However, the age effect should be retested with a larger cohort to increase the statistical force. Overall, chronological age does not appear to be a determinant of the success of the $3 \mathrm{i}$ method.

\section{Comparing the $3 i$ (individual, interactive and intensive) method with other ASD children interventions} Individualising the intervention through considering the developmental stage and specific needs of the child can occur via the one-on-one context and the focus on the child's development through meetings with the psychologist of the 3i method. Studies on the Denver approach [19] support the idea that using a developmental perspective is more efficient. Our prospective study, similar to our previous retrospective study on $120 \mathrm{pa}$ tients, is in line with this view.

\section{Playing as a support for interaction}

In terms of play therapies and the $3 \mathrm{i}$ method, Gardziel et al. previously commented on the positive aspects of the $3 \mathrm{i}$ method and described its beneficial effects on one ASD patient [35]. In another study, the progress of 3 ASD patients treated with the $3 \mathrm{i}$ method was assessed using the BECS,
PEP-3 and CARS [47]. After 2 years of receiving the 3i method, the 3 children showed a positive evolution: they had less invasive autistic disorders and communicated and interacted more with others. Additionally, a retrospective single case study on a 2-year-old boy treated for 30 months with the $3 \mathrm{i}$ method reported a 9.5 point decrease in his CARS score, placing him below the threshold for autism; furthermore, his 3 ADI-R scores, which were all impaired at baseline, were shown to be out of the autistic diagnosis range when assessed after 10 years of follow-up (Astrup O: An individual study of an autistic child over a nine years period using the $3 \mathrm{i}$ method, in preparation). Finally, another retrospective study on 120 children treated for 2 years with the 3i method (Favrot C, Saint-Georges-Chaumet Y, SaintGeorges C: Evaluation of the efficiency of the 3i method from a retrospective archive study on 120 children diagnosed with Autism Spectrum Disorders, submitted) and assessed by a skill-building stage scale seems to be in line with our results: on average, the subjects acquired a higher stage of competence in four of the six skill areas (Imitation, Gaze Quality, Social and Emotional Regulation, Verbal Expression, Non-Verbal Expression and Verbal Comprehension), with a greater increase in the skills of imitation and non-verbal communication. The present study prospectively shows for the first time the benefit that ASD patients can receive from intensive play therapy with the $3 \mathrm{i}$ method. These results are in line with those of other studies on play therapy: Floor Time [14, 17], "Exchange and Development Therapy" [15], and SonRise [12]; ESDM also partially uses play therapy components. All these play therapy methods share a developmental vision in which the child can succeed in building relational abilities through repeated experiences in individual relationships with responsive, joyful and empathic adults, before learning to face other children. This primary dyadic context may be crucial for the development of the first stages of relational abilities. In the Floortime study, the 31 children who received 14 weekly hours of play with their parents progressed in skills within 1 year at the Functional Emotional 
Assessment Scale (FEAS) and at the Functional Emotional Developmental Questionnaire (FEDQ) and exhibited a mean decrease of 3 points in their CARS score. The SonRise study showed a significant effect of an intensive week $(40 \mathrm{~h}$ ) of treatment in 6 children (compared to 6 control children) on interaction and communication measures. All these studies support the idea of efficiency of stimulating through a play adapted to the developmental level of the child, and our results are in line with that view.

Play support, tailoring to child developmental level and structuration are aspects of the $3 \mathrm{i}$ method that are similar to "Exchange and Development Therapy" (EDT) [15]. Thirty-five children aged 2 to 7 years old treated with this method for a 9-month period improved their skills in imitation, joint attention and interaction (on the BECS scale) and exhibited a decrease in interaction and communication disorders (in the ECA-R). Although the mean age, scales and length of observation differ, these results are congruent with those of our study. However, although the EDT children had a few sessions per week and received other interventions simultaneously (daycare hospital, school inclusion, etc.), intensivity (at least $30 \mathrm{~h}$ a week) and the use of volunteers at home are specific in the $3 \mathrm{i}$ method. This study suggests that a developmental play-therapy method can be intensive without mobilizing many professionals and alone is able to allow the child to progress in key areas of development.

Intensivity (several hours a day) is recommended by Narzisi [27] based on his literature review. Behavioural approaches and the Denver Method often stress this need for intensivity. Once autistic syndrome is installed and stable, repetition of therapeutic interactive experiences may be crucial to allow new functioning and new brain circuitry to develop and finally outgrow autistic functioning. This study, similar to the SonRise study [12], shows that play-therapy can be intensive and provides encouraging results.

Parental implication Another interesting point that makes the 3i method different from SonRise or EDT is the importance of including parents in the therapy. In the $3 \mathrm{i}$ approach, parents must recruit volunteers, accommodate them at home and coordinate their interventions; they sometimes participate in planning the intervention themselves. They are involved in the care and thus are led to change their comprehension of their child and the quality of their daily interactions with them. As mentioned in the introduction, some studies have reported a positive impact of parental participation [29-32, 47]. Their inclusion may help extend the beneficial effects of treatment even outside the time allotted for therapy. Our study again underlines the benefit of involving parents. However, for the 3 patients who were treated in a centre instead of in their private homes, no significant differences were found in their outcomes compared to those of the 17 home-treated patients. These data suggest that the place of intervention may not affect the treatment outcome, but additional data are necessary with a larger sample to really assess this effect.

Voluntaries intervention Interacting with ASD children represents the utmost difficulty. In the $3 \mathrm{i}$ method, the presence of volunteers, non-professionals and their large number is an asset, for several reasons. First, as a play-based method in which it is crucial to adapt to the level of the child and be creative, the large number of volunteers allows them to spend only $1.5 \mathrm{~h}$ twice a week and consequently not be exhausted by the bewildering behaviours of the child, allowing them to remain creative and at the child's disposal. This short time spent with the autistic child could be a powerful factor to prevent the adult's discouragement and the corresponding withdrawal effects that may occur in the child when he perceives the negative or depressed attitude of the adult. Second, it is an ecological framework because the team of volunteers consists of a few family relatives (parents and grandparents) and other adults chosen by the parents in their immediate environment. This allows the child to be part of his social and cultural life, favouring insertion and recognition in a community. Moreover, this team, which is quite diverse in age and sex, corresponds to the population that the child will encounter in ordinary life. The group of volunteers represents a first positive and warm social experience, allowing the child to socialize gradually in a friendly living environment.

Specificities and prospects for education A progression to higher scores in our sample was observed in VABS socialization (90\% mean increase), PEP-R imitation (+61\%), Nadel imitation $(+49 \%)$ and ADI interaction $(-45 \%)$. These results are consistent because socialization, imitation and interaction are domains that appear to be directly or indirectly linked. Interestingly, although these children had not been "socialized" at school, the greatest improvements were observed in socialization. Peer-to-peer immersion is thus not the only way to "socialize", and an alternative method could be used to improve interactive and relational functioning in a privileged system with responsive adults before joining the school system. This suggests that first acquiring the ability to be in a relationship, before learning how to adapt to peers and an institution, may be beneficial for ASD patients. This reflects the specific aim of AEVE: to promote the socialization and communication of ASD children to allow them to integrate into a regular school system.

Limitations of the study must, however, be noted. First, this was a prospective non-controlled study. Indeed, from an ethical and practical point of view, it was impossible to 

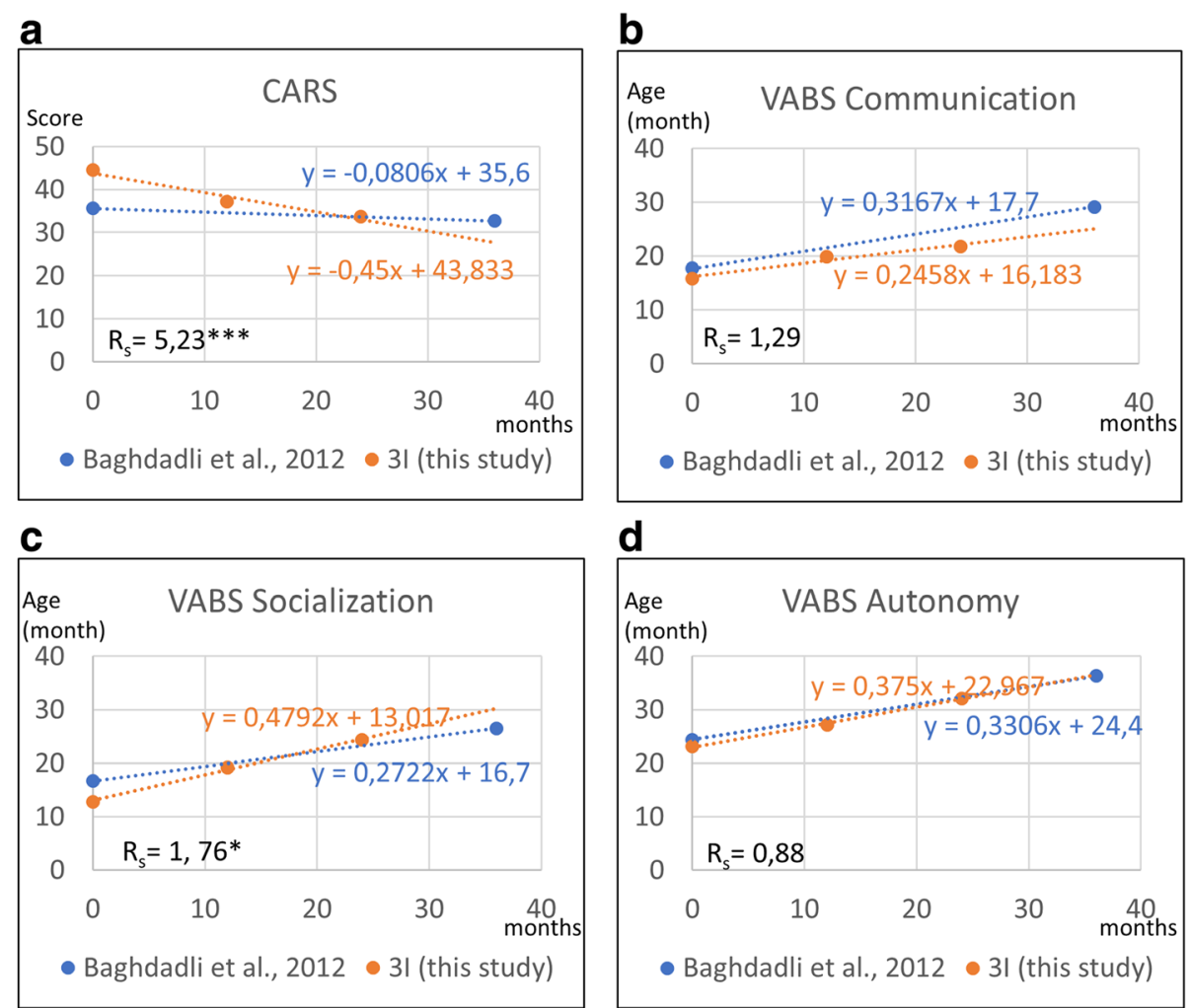

Fig. 3 Comparison of evolution of CARS and VABS scores between 24 months of 31 methods (this study) and 36 months of standard treatment in centers according to Baghdadli et al., [48]. Evolution of the mean scores of CARS (panel a), VABS communication (Panel b), VABS socialization (Panel $\mathbf{c}$ ) and VABS autonomy (Panel $\mathbf{d}$ ) are represented in graphs. A linear regression was calculated for each treatment and the related equations are represented in the graphic. The ratio of the slopes (R s) indicate difference between the evolution of scores of Baghdadli et al., [48] and this study. A P-value calculated with the one sample t-test compare the distribution of the slope calculated for each subject with the mean slope of Baghdadli et al., [48]. ${ }^{*} p$-value $<0.05 ;{ }^{* *} p$-value $<0.01 ;{ }^{* *} p$-value $<0.001$

find subjects who had not received any ASD treatment for 2 years. However, in the absence of a control group, we attempted to compare our results with data from Baghdadli et al., 2012, over a 3-year period [48]. The authors used CARS and VABS tests to assess the mean developmental trajectories of autism severity and adaptive behaviours in 152 children (mean age 4.9) who were treated with various interventions (median $28 \mathrm{~h} /$ week, including schooling, educational therapy, physiotherapy and speech therapy) in dozens of French centres. Figure 3 shows that the slope of CARS decreases 5.23-fold more in 3i children compared to Baghdadli's cohort (Fig. 3a). Considering changes in VABS developmental ages (in months) in $3 \mathrm{i}$ children compared to Baghdadli's cohort, communication scores increased 1.29fold less (Fig. 3b), socialization scores increased 1.76-fold more (Fig. 3C) and autonomy scores increased 1.13-fold more (Fig. 3D). These data suggest that although progress in communication and autonomy seem to be equivalent between the $3 \mathrm{i}$ method and various other treatments, progress in socialization may be noteworthy with the $3 \mathrm{i}$ method. In addition, the overall autism severity assessed by CARS seemed to decrease importantly in $3 \mathrm{i}$ patients compared to
Baghdadli's cohort. Another limitation of this study was the limited size of our sample. Although our previous retrospective study showed a positive evolution in 120 children (Favrot C, Saint-Georges-Chaumet Y, Saint-Georges $\mathrm{C}$ : Evaluation of the efficiency of the $3 \mathrm{i}$ method from a retrospective archive study on 120 children diagnosed with Autism Spectrum Disorders, submitted), a prospective controlled study in a larger sample is necessary. The large age range could also limit the statistical power and interpretation. However, excluding older patients would have decreased the inclusivity. Regardless, age did not seem to affect the outcomes in our study (Additional file 2: Tables S1 and S3). A larger study would be necessary to confidently state the effect of age on the 3i method's efficiency. Finally, the $3 \mathrm{i}$ method is to be considered an experimental intervention in ASD. The method is still not manualized and standardized. However, 3i Method has been described in English [49], and the AEVE has developed a typical training program for psychologists enriched by filmed training materials. Hence, the replication of the $3 \mathrm{i}$ method is possible all over the world provided that national ASD experts are appropriately trained in France (to ensure easy 
recruitment and supervision of volunteers, setting-up of play rooms and monitoring of patients) and then become $3 \mathrm{i}$ trainers in their country. The $3 \mathrm{i}$ method has been already replicated in Poland at the request of the Malta Center for handicapped children in Cracow [35, 37]. One Polish ASD professional was trained in France and then provided 3i training to all professionals of the Center, where the $3 \mathrm{i}$ method became the primary therapy for autism. In subsequent years, the Malta Center expanded the "METODA 3i" to various locations in Poland (centers, schools, foundations in Cracow, Lublin; Warsaw, Hrubierszów and Bydgoszcz) under the conceptual and educational supervision via "AEVE Poland".This supervision is operated through organized exchange of information and the annual visit of a French 3i expert. Moreover, the method is well known by local Universities of which many students are volunteer in 3i teams. Since September 2017 the 3i method is also replicated in Volos (Greece) by a Greek psychologist trained in France. Lastly, two teachers of a school for mentally handicapped persons in Hangzhou (China) were $3 \mathrm{i}$ trained in November 2017, with a view to implementing the method in this school. Thus, 3i method could be developed in various countries and represent cost-effective alternatives. Manualizing the method in the future is highly considered.

\section{Conclusions}

This is the first prospective study to suggest the positive effects of the 3i method on behavioural and developmental skills and on ASD severity. The results presented in this study are in line with previous retrospective studies on the $3 \mathrm{i}$ intervention. They are also consistent with other methods using play therapy but may represent an advantage of the 3i method because it is less expensive. Further studies are necessary to support these initial results.

\section{Additional files}

Additional file 1: Protocol accepted by the French agency for health and drug (ANSM) under the number ID-RCB 2014-A00542-45, reference: B148558-31 (DOCX 57 kb)

Additional file 2: Table S1. Individual results of the ADI-R, CARS, VABS, PEP-R and IMITATION (Nadel) tests for all participant of the study. Table S2. Mean ratio of the results between $\mathrm{T} 2$ an T0 of the different scores of this study of the 17 children followed at home and the 3 subjects followed in center. Table S3. Mean ratio of the results between T2 an T0 of the different scores of this study of the 16 children under 6 years old and the 4 subjects aged more than 7 years old. (DOCX $45 \mathrm{~kb}$ )

\section{Abbreviations}

ABA: Applied behaviour analysis; AD: Autistic disorder; ADI-R: Autism diagnostic interview - revised; AEVE: Association autisme espoir vers l'ECole; ASD: Autism spectrum disorders; CARS: Child autism rating scale; DIR: Individual differences and relationship-based; DQ: Developmental quotient; DSM: Diagnostic and statistical manual of mental disorders; EDT: Exchange and development therapy; ESDM: Early start denver model; ID: Intellectual disability; NIS: Nadel imitation scale; PDD-NOS: Pervasive developmental disorder-not otherwise specified PEP-R: Psycho-educational profile - revised; TEACCH: Therapy of education of autistic and related communication handicapped cHildren; VABS: Vineland adaptive behaviour scale

\section{Funding}

This work was supported by the Fondation Bettencourt Schueller, the Fondation Deheca Institut de France, the Fondation Paul Parquet and the Fondation Antoine de Saint-Exupéry pour la Jeunesse. None of these funding bodies have a role in the in the design of the study collection, analysis, and interpretation of data and in writing the manuscript.

\section{Availability of data and materials}

The datasets used and/or analysed during the current study are available from the corresponding author on reasonable request.

\section{Authors' contributions}

Data collection: ET; Study design: CSG; Data analysis: YSGC, CSG, DC; Writing: CSG, YSGC, CF, AT, DC. All authors have read and approved the final manuscript.

\section{Ethics approval and consent to participate}

The protocol of this study was approved by the ethical committee (Comité de Protection des Personnes lle de France 1) under the number 2014-Juin-13,594 and was registered by the French Agency for drug and health (ANSM) under ID RCB number 2014-A00542-45 and ANSM referenceB148558-31. A signed informed consent was required from the parents before the enrolments of the subjects.

\section{Competing interests}

ET is a psychologist paid by AEVE to assess patients. YSGC was paid by AEVE to perform the statistical analysis and to participate in article writing. CF, AT, DC and CSG declare no conflicts of interest.

\section{Publisher's Note}

Springer Nature remains neutral with regard to jurisdictional claims in published maps and institutional affiliations.

\section{Author details}

${ }^{1}$ Cabinet privéé, 16 Avenue de la gares, 91570 Bievre, France. ${ }^{2}$ Bioredac, 97 grande rue, 78240 Chambourcy, France. ${ }^{3}$ Regional Psychiatric Center for Child and Adolescent with Deafness, 1st intersecteur, 64 rue de la glacière, 75013 Paris, France. ${ }^{4}$ Department of Child and Adolescent Psychiatry, Hôpital de la Pitie-Salpêtriere, University Pierre and Marie Curie, 75013 Paris, France. ${ }^{5}$ Institut des Systèmes Intelligents et de Robotiques, CNRS UMR 7222, Université Pierre et Marie Curie, Paris, France.

Received: 3 March 2017 Accepted: 30 April 2018

Published online: 12 May 2018

\section{References}

1. American Psychiatric Association. Diagnostic and Statistical Manual of Mental Disorders [Internet]. Washington: American Psychiatric Association: 2013 [cited 2016 Jul 5]. Available from: https://dsm.psychiatryonline.org/doi/ book/10.1176/appi.books.9780890425596.

2. Lainé F, Rauzy S, Tardif C, Gepner B. Slowing down the presentation of facial and body movements enhances imitation performance in children with severe autism. J Autism Dev Disord. 2011 [cited 2016 Jul 5]:41:983-996. Available from: https://link.springer.com/article/10.1007\%2Fs10803-010-1123-7.

3. Barthelemy C, Adrien JL, Tanguay P, Garreau B, Fermanian J, Roux S, et al. The behavioral summarized evaluation: validity and reliability of a scale for the assessment of autistic behaviors. J Autism Dev Disord. 1990 [cited 2016 Jul 5]: 20:189-204. Available from: http://www.ncbi.nlm.nih.gov/pubmed/2347819.

4. Adrien JL, Martineau J, Barthélémy C, Bruneau N, Garreau B, Sauvage D. Disorders of regulation of cognitive activity in autistic children. J Autism Dev Disord. 1995 [cited 2016 Jul 5];25:249-263. Available from: http://www. ncbi.nlm.nih.gov/pubmed/7559291

5. Voineagu I, Yoo HJ. Current progress and challenges in the search for autism biomarkers. Dis Markers. 2013 [cited 2016 Nov 28];35:55-65. Available from: https://www.hindawi.com/journals/dm/2013/476276/.

6. Kasari C, Gulsrud A, Freeman S, Paparella T, Hellemann G. Longitudinal followup of children with autism receiving targeted interventions on joint attention and play. J Am Acad Child Adolesc Psychiatry. 2012 [cited 2017 Jan 17];51:487495. Available from: http://www.ncbinlm.nih.gov/pubmed/22525955. 
7. Eikeseth S. Outcome of comprehensive psycho-educational interventions for young children with autism. Res Dev Disabil. 2009 [cited 2016 Dec 15];30: 158-178. Available from: http://www.ncbi.nlm.nih.gov/pubmed/18385012.

8. Vismara $L A$, Rogers SJ. Behavioral treatments in autism spectrum disorder: what do we know? Annu Rev Clin Psychol. 2010 [cited 2016 Jul 25];6:447468. Available from: http://www.ncbi.nlm.nih.gov/pubmed/20192785.

9. Eapen V, Crnčec R, Walter A. Clinical outcomes of an early intervention program for preschool children with autism Spectrum disorder in a community group setting. BMC Pediatr. 2013 [cited 2016 May 27];13:3. Available from: https://www. ncbi.nIm.nih.gov/pmc/articles/PMC3631131/?tool=pmcentrez.

10. Koegel RL, Koegel LK, McNerney EK. Pivotal areas in intervention for autism. J Clin Child Adolesc Psychol. 2001;30:19-32. Available from: https://www. tandfonline.com/doi/abs/10.1207/S15374424JCCP3001_4.

11. Virues-Ortega J, Julio FM, Pastor-Barriuso R. The TEACCH program for children and adults with autism: a meta-analysis of intervention studies. Clin Psychol Rev. 2013;33:940-953. Available from: https://www.ncbinlm.nih.gov/ pubmed/23988454.

12. Houghton K, Schuchard J, Lewis C, Thompson CK. Promoting child-initiated social-communication in children with autism: son-rise program intervention effects. J Commun Disord. 2013;46:495-506. Available from: http://www.ncbi.nlm.nih.gov/pubmed/24209427.

13. Greenspan SI. Autism. N Engl J Med. 1997;337:1556; author reply 1556-7. Available from: https://www.ncbi.nlm.nih.gov/pubmed/9380126.

14. Pajareya K, Nopmaneejumruslers K. A pilot randomized controlled trial of DIR/Floortime ${ }^{\text {TM }}$ parent training intervention for pre-school children with autistic spectrum disorders. Autism. 2011 [cited 2016 Jul 5];15:563577. Available from: http://www.ncbi.nlm.nih.gov/pubmed/21690083.

15. Blanc R, Malvy J, Dansart P, Bataille M, Bonnet-Brilhault F, Barthélémy C. La thérapie d'échange et de développement, Une rééducation neurofonctionnelle de la communication sociale. Neuropsychiatr Enfance Adolesc. 2013;61:288-94. Available from: http://linkinghub.elsevier.com/ retrieve/pii/S0222961713000779.

16. Wieder S, Greenspan SI. Climbing the symbolic ladder in the DIR model through floor time/interactive play. Autism. 2003 [cited 2017 Jan 17];7:425435. Available from: http://www.ncbi.nlm.nih.gov/pubmed/14678681.

17. Pajareya K, Nopmaneejumruslers K. A one-year prospective follow-up study of a DIR/Floortime "'m parent training intervention for pre-school children with autistic Spectrum disorders. J Med Assoc Thail. 2012:95:1184-93.

18. Macalpine M. Play in autism: the power of microdevelopment. 1999.

19. Dawson G, Rogers S, Munson J, Smith M, Winter J, Greenson J, et al. Randomized, controlled trial of an intervention for toddlers with autism: the early start Denver model. Pediatrics. 2010 [cited 2016 Jan 15];125:e17-e23. Available from: http://www.ncbi.n/m.nih.gov/pubmed/19948568.

20. Dawson G, Jones EJH, Merkle K, Venema K, Lowy R, Faja S, et al. Early behavioral intervention is associated with normalized brain activity in young children with autism. J Am Acad Child Adolesc Psychiatry. 2012;51:1150-9. Available from: http://www.ncbi.nlm.nih.gov/pubmed/23101741.

21. Rogers SJ, Vismara L, Wagner AL, McCormick C, Young G, Ozonoff S. Autism treatment in the first year of life: a pilot study of infant start, a parentimplemented intervention for symptomatic infants. J Autism Dev Disord. 2014 [cited 2016 Jul 5];44:2981-2995. Available from: http://www.ncbi.nlm. nih.gov/pubmed/25212413.

22. Koegel RL, Bradshaw JL, Ashbaugh K, Koegel LK. Improving question-asking initiations in young children with autism using pivotal response treatment. J Autism Dev Disord. 2014 [cited 2016 Jul 5]:44:816-827. Available from: http://www.ncbi.nlm.nih.gov/pubmed/24014174.

23. Poinso F, Dubois B, Chatel C, Viellard M, Bastard-Rosset D, Girardot A-M, et al. Prospective assessment of children with pervasive developmental disorder after 2 years of day-hospital treatment. Arch pédiatrie organe Off la Sociéte Fr pédiatrie. 2013;20:17-25. Available from: http://www.ncbi.nlm.nih. gov/pubmed/23219270.

24. Schröder CM, Florence E, Dubrovskaya A, Lambs B, Stritmatter P, Vecchionacci $V$, et al. Le modèle de Denver (early start Denver model). Une approche d'intervention précoce pour les troubles du spectre autistique. Neuropsychiatr Enfance Adolesc. 2015;63:279-87. Available from: https://www.sciencedirect.com/science/article/pii/ S0222961715000768?via\%3Dihub.

25. Pry R, Bodet J, Pernon E, Aussilloux C, Baghdadli A. Initial characteristics of psychological development and evolution of the young autistic child. J Autism Dev Disord. 2007 [cited 2016 Jul 5];37:341-353. Available from: http://www.ncbi.nlm.nih.gov/pubmed/16897385.
26. Tanet A, Hubert-Barthelemy A, Crespin GC, Bodeau N, Cohen D, SaintGeorges C, et al. A developmental and sequenced one-to-one educational intervention for autism Spectrum disorder: a randomized single-blind controlled trial. Front Pediatr. 2016 [cited 2016 Oct 31];4:99. Available from: http://www.ncbi.nlm.nih.gov/pubmed/27725927.

27. Narzisi A, Costanza C, Umberto B, Filippo M. Non\-pharmacological treatments in autism spectrum disorders: an overview on early interventions for pre-schoolers. Curr Clin Pharmacol. Bentham Science Publishers; 2014 [cited 2016 Jul 5];9:17-26. Available from: http://www.ncbi.nlm.nih.gov/ pubmed/24050743.

28. Gattegno M. La prise en charge des personnes avec autisme et troubles envahissants du développement : I'intervention adaptée et individualisée. Approch Neuropsychol des Apprentissages chez l'Enfant. 2008:305-10.

29. Rickards AL, Walstab JE, Wright-Rossi RA, Simpson J, Reddihough DS. A randomized, controlled trial of a home-based intervention program for children with autism and developmental delay. J Dev Behav Pediatr. 2007 [cited 2016 Jul 5];28:308-316. Available from: http://www.ncbi.nIm.nih.gov/ pubmed/17700083.

30. Green J, Charman T, McConachie H, Aldred C, Slonims V, Howlin P, et al. Parent-mediated communication-focused treatment in children with autism (PACT): a randomised controlled trial. Lancet (London, England). 2010 [cited 2016 Oct 20];375:2152-2160. Available from: http://www.ncbi.nlm.nih.gov/ pubmed/20494434.

31. Venker CE, McDuffie A, Ellis Weismer S, Abbeduto L. Increasing verbal responsiveness in parents of children with autism:a pilot study. Autism. 2012 [cited 2017 Jan 17];16:568-585. Available from: http:/www.ncbi.nlm. nih.gov/pubmed/21846665.

32. Wetherby AM, Guthrie W, Woods J, Schatschneider C, Holland RD, Morgan $L$, et al. Parent-implemented social intervention for toddlers with autism: an RCT. Pediatrics. 2014 [cited 2017 Jan 17];134:1084-1093. Available from: http://www.ncbi.nlm.nih.gov/pubmed/25367544.

33. Pickles A, Le Couteur A, Leadbitter K, Salomone E, Cole-Fletcher R, Tobin $\mathrm{H}$, et al. Parent-mediated social communication therapy for young children with autism (PACT): long-term follow-up of a randomised controlled trial. Lancet. 2016 [cited 2017 Jan 26];388:25012509. Available from: http://www.ncbi.nlm.nih.gov/pubmed/27793431.

34. Thompson CK, Jenkins T. Training parents to promote communication and social behavior in children with autism: the son-rise program. J Commun Disord Deaf Stud Hear Aids. 2016:4 Available from: http://www. esciencecentral.org/journals/training-parents-to-promote-communicationand-social-behavior-inchildren-with-autism-the-sonrise-program-2375-44271000147. php?aid=66836.

35. Gardziel A, Ozaist P, Sitnik E. Method 3i in ASD therapy. Psychoterapia. 2015: 172:37-45. Available from: http://www.psychoterapiaptp.pl/uploads/PT_1_ 2015/37Gardziel_PT2015i1.pdf.

36. Nadel J, Potier C. Imitez, imitez, il en restera toujours quelque chose : le statut développemental de l'imitation dans le cas d'autisme. Enfance. 2002 [cited 2017 Jan 17];54:76. Available from: https://www.cairn.info/revueenfance1-2002-1-p-76.htm.

37. Ozaist P. $3 i$ - Intensity, individuality, interactivity - in the treatment of children with autism. In: Palak Z, Wójcik M, editors. Ter Pedagog dzieci ze Spec potrzebami Rozw i Eduk Nome oblicza Ter w Pedagog Spec. Université. Lublin: UMCS; 2016. p. 137-48.

38. Scarpa O, François M, Gobert L, Bourger P, Dall'Asta A, Rabih M, et al. L'imitation au service de l'autisme: Une étude pilote. Enfance. 2012;2012:389-410. Available from: https:/www.cairn.info/revue-enfance2-2012-4-page-389.htm.

39. Sparrow SS, Balla DA, Cicchetti DV. Vineland adaptive behavior scales. MN: Circle Pines: Service, A; 1984

40. Bracken BA, Nagle RJ, Richard J. Psychoeducational Assessment of Preschool Children. (Francis T \&, ed.). London: Lawrence Erlbaum Associates; 2004. https:// books.google.fr/books?hl=fr\&lr=\&id=03VYD8NJFjgC\&oi=fnd\&pg=PP1\&dq= Psychoeducational +assessment+of+preschool+children\&ots=G01R453fFh\&sig= M-bT_8uEZMHHjov9OaiR25SbdWU\#v=onepage\&q=Psychoeducational assessment of preschool children\&f=false. Accessed 14 Dec 2017.

41. Schopler E, Reichler RJ. Profil psycho-éducatif (PEP-R) : évaluation et intervention individualisée pour enfants autistes ou présentant des troubles du développement. Louvain-la-Neuve: De Boeck-Wesmael; 1994.

42. Alwinesh MTJ, Joseph RBJ, Daniel A, Abel JS, Shankar SR, Mammen P, et al. Psychometrics and utility of psycho-educational profile-revised as a developmental quotient measure among children with the dual disability of 
intellectual disability and autism. J Intellect Disabil. SAGE PublicationsSage UK: London, England; 2012 [cited 2017 Dec 14];16:193-203. Available from: http://journals.sagepub.com/doi/10.1177/1744629512455594.

43. Lord C, Rutter M, Le Couteur A. Autism diagnostic interview-revised: a revised version of a diagnostic interview for caregivers of individuals with possible pervasive developmental disorders. J Autism Dev Disord. 1994;24: 659-85. Available from: http://www.ncbi.nlm.nih.gov/pubmed/7814313.

44. Schopler E, Reichler RJ, DeVellis RF, Daly K. Toward objective classification of childhood autism: childhood autism rating scale (CARS). J Autism Dev Disord. 1980;10:91-103. Available from: http://www.ncbi.nlm.nih.gov/ pubmed/6927682.

45. Hamer RM, Simpson PM. Last observation carried forward versus mixed models in the analysis of psychiatric clinical trials. Am J Psychiatry. 2009 [cited 2016 Jul 28];166:639-641. Available from: http://www.ncbi.nlm.nih. gov/pubmed/19487398.

46. American Psychiatric Association. Diagnostic and Statistical Manual of Mental Disorders IV-TR [Internet]. Washington: American Psychiatric Association; 2000. Available from: http://psychiatryonline.org/doi/book/10. 1176/appi.books.9780890425596.

47. Mahoney G, Wheeden CA, Perales F. Relationship of preschool special education outcomes to instructional practices and parent-child interaction. Res Dev Disabil. 2004 [cited 2017 Jan 26];25:539-558. Available from: http:// www.ncbi.nlm.nih.gov/pubmed/15541631.

48. Baghdadli A, Assouline B, Sonié S, Pernon E, Darrou C, Michelon C, et al. Developmental trajectories of adaptive behaviors from early childhood to adolescence in a cohort of 152 children with autism Spectrum disorders. J Autism Dev Disord. 2012;42:1314-25. Available from: http://link.springer. com/10.1007/s10803-011-1357-z.

49. AEVE. The triple "I" Programme intensive -individualised -interactive [internet]. 2012 [cited 2018 Mar 11]. p. 15. Available from: http://autismeespoir.org/anglais/triple---programme.pdf.

\section{Ready to submit your research? Choose BMC and benefit from:}

- fast, convenient online submission

- thorough peer review by experienced researchers in your field

- rapid publication on acceptance

- support for research data, including large and complex data types

- gold Open Access which fosters wider collaboration and increased citations

- maximum visibility for your research: over $100 \mathrm{M}$ website views per year

At BMC, research is always in progress.

Learn more biomedcentral.com/submissions 